educational activities; some of them are also involved in volunteer activities regarding education of children and adolescents for injury prevention and safety promotion, such as programs developed by the Organisation of Medical Students or the Department of Community Medicine from the university. Training and involvement in the field of research, capacity building and cooperation have several weaknesses, but examples of some activities of research developed by few medical students can be also presented.

Conclusions The presentation underlines the strengths and weaknesses and makes recommendations for future improvements regarding the presented issues.

\section{GROUP AND ORGANISATIONAL SAFETY CLIMATE IN THE FIRE SERVICE: PSYCHOMETRIC PILOT STUDY RESULTS}

${ }^{1}$ Todd D Smith, ${ }^{2}$ David M DeJoy, ${ }^{3}$ Mari-Amanda (Aimee) Dyal. ${ }^{1}$ Indiana University School of Public Health - Bloomington; ${ }^{2}$ University of Georgia, College of Public Health; ${ }^{3}$ Kennesaw State University

\subsection{6/injuryprev-2016-042156.1003}

Objectives Research related to safety climate in fire service organisations is limited. The researchers initiated a large-scale safety climate study in the fire service in the eastern and western United States.

Methods The researchers have completed extensive qualitative research to identify and refine the dimensions of safety climate in the fire service and to refine the model guiding the research. Pilot data were collected from 208 firefighters in Georgia. Psychometric analyses were completed to assess reliability and validity.

Results Psychometric analyses identified reliable scales. Grouplevel factors derived include supervisor support ( $\alpha=0.91)$, vertical cohesion $(\alpha=0.92)$, and horizontal cohesion $(\alpha=0.94)$. Key organisational factors derived include management commitment $(\alpha=0.95)$ and programs/policies $(\alpha=0.95)$. Other organisational factors included human resource management $(\alpha=0.85)$ and incident command $(\alpha=0.92)$. Safety behaviour scales were also derived, including safe work practices ( $\alpha=0.79$ ), personal protective equipment use $(\alpha=0.85)$, safety citizenship behaviour $(\alpha=0.96)$, safety voice $(\alpha=0.87)$ and employee rights and responsibilities $(\alpha=0.79)$. Correlations between these latent factors were mostly highly significant. The only relationships not significant were between human resource management and safety citizenship behaviour and human resource management and personal protective equipment.

Discussion Research within fire service organisations has been limited. This novel work provides some initial exploration into safety climate factors within the American fire service. The initial factors, which were psychometrically determined and analysed, provide initial guidance for future safety climate research in the fire service and provide information that practitioners can use to explore safety climate within fire and emergency service organisations.

\section{KNOWLEDGE, ATTITUDE AND PRACTICE REGARDING WORK SAFETY CULTURE AMONG STAFF IN A PUBLIC UNIVERSITY IN MALAYSIA}

${ }^{1}$ Titi Rahmawati Hamedon, ${ }^{1}$ Rosliza A Manaf, ${ }^{2}$ Izzatiey Amerah Aziz, ${ }^{2}$ Muhammad Syukran Idris. 'Department of Community Health, Faculty of Medicine and Health Sciences, Universiti Putra Malaysia, Malaysia; ${ }^{2}$ Faculty of Medicine and Health Sciences, Universiti Putra Malaysia, Malaysia

\subsection{6/injuryprev-2016-042156.1004}

Background Safety culture of an institution is the reflection of actions, attitudes and behaviour of its members concerning safety. A good safety culture in an academic institution impacts on the quality of work and improves organisational performance. This paper aims to explore the knowledge, attitude and practice (KAP) on work safety culture (WSC) among a sample of academic and non-academic staffs in a university in Malaysia.

Methods A cross-sectional study using self-administered questionnaire was conducted among 215 academic and non-academic staffs in a medical faculty in Malaysia.

Results In general, 73.8\% have good knowledge regarding WSC, $54.5 \%$ reported positive attitude regarding WSC and $74.1 \%$ practiced good WSC. Bivariate analysis was performed to examine the association between participants' KAP and several sociodemographic characteristics, as well as employment factors, followed by multivariate analysis to identify the predictors of KAP. Knowledge level on WSC was significantly associated with length of services, where participants who worked for less than eight years reporting better knowledge on WSC compared to their colleague with longer service duration (adjusted odds ratio, $\mathrm{AOR}=1.76 ; 95 \%$ confidence interval, $\mathrm{CI}:=1.21,3.53)$. Positive attitude regarding WSC was significantly associated with being permanently employed compared to temporary employment $(\mathrm{AOR}=2.72 ; 95 \% \mathrm{CI}:=1.11,6.64)$, whereas the practice of good WSC was significantly associated with having good knowledge on WSC (adjusted OR $=4.91,95 \%$ CI: 2.42,10.75), having good attitude towards WSC (adjusted OR $=2.22,95 \%$ $\mathrm{CI}: 1.07,4.62$ ) and being married (adjusted $\mathrm{OR}=2.64,95 \% \mathrm{CI}$ : $1.13,6.16)$

Conclusions This study concludes that good knowledge and positive attitude being important factors in determining good safety practice among the participants. While employment characteristics have shown significant association with knowledge and attitude, these did not determine the participants' practice on WSC. Therefore, appropriate education and safety promotion need to be given to all members of the faculty regardless of their sociodemographic and employment status to ensure optimum safety practices in the organisation.

\section{PREVENTION OF ACCIDENTS IN SMALL AND MEDIUM ENTERPRISES (SMES) IN DELHI CITY OF INDIA}

PK Goswami, Deputy Director. Labour Department, Government of Delhi

\subsection{6/injuryprev-2016-042156.1005}

Background Great efforts are directed towards the advancement of Small and medium Enterprises (SME) in developing countries. SMEs are considered as the driving force for the economic growth of a developing country like India. According to WHO, over 1000 million people worldwide are employed in SME industries. In India about 70\% workforce are working in SMEs of unorganised sector. It provides employment for both men and women, mainly those from the lower socioeconomic classes. 